\title{
Contribution of the CASA system, based on open source software, to the assessment of sperm characteristics: informetric and usage-based approaches
}

\section{Giovano Neumann $^{1 *}$, Jurandir Joaquim Bernardes Júnior ${ }^{2}$, Paulo Vanderlei Sanches ${ }^{1}$, Pitágoras Augusto Piana ${ }^{1}$, Robie Allan Bombardelli ${ }^{1}$}

\begin{abstract}
${ }^{1}$ Universidade Estadual do Oeste do Paraná, Programa de Pós-graduação em Recursos Pesqueiros e Engenharia de Pesca, Grupo de Pesquisas em Recursos Pesqueiros e Limnologia, Toledo, PR, Brazil.

${ }^{2}$ Universidade Federal de Santa Catarina, Programa de Pós-graduação em Aquicultura, Laboratório de Biologia e Cultivo de Peixes de Água Doce, Florianópolis, SC, Brazil.
\end{abstract}

\begin{abstract}
By using informetric tools, we evaluated the contribution and impact of the open source computer-assisted sperm analysis (CASA) software on sperm studies, especially pertaining to fish. The article was cited 125 times between 2007 and 2014 in four publication types (articles, doctoral dissertations, master's theses, and books). Among articles, the number of citations increased at rate of three citations per year and the calculated h-index was 17. Of the studies that cited Wilson-Leedy and Ingermann (2007), fish were the main group of organisms studied (61 articles); of these, 34 articles used the open source CASA, covering 23 marine or freshwater species. Studies conducted in 12 countries were published in 21 journals. Four ways of knowledge sharing were identified: by direct partnership with the system developers; by knowledge multipliers, who worked directly with the system developers; by groups that adopted the system by their own initiative; and through expansion of cooperation networks with autodidacts. In regard to specific analytical procedures, motility, curvilinear velocity, average path velocity, and straight-line velocity were the main CASA parameters used to describe sperm movements. As expected, the usage of this tool has been increasing over the years, being a reliable and versatile alternative to more costly similar platforms. However, the potential of the CASA system has not been completely explored and it is our assessment that some results produced by CASA are poorly understood or even misunderstood.
\end{abstract}

Key Words: computational analysis, fish, motility, scientometry, spermatozoa

\section{Introduction}

The first attempts of objective analyses of sperm movements using film-based technology were conducted by andrologists in 1940. Following the evolution of computers a few decades later (in the 1970s), biologists and spermatologists began to use this newly developed technology to evaluate movements of microscopic organisms, including sperm (Amann and Katz, 2004; Amann and Waberski, 2014).

In 1975, a new computer-assisted sperm analysis (CASA) system for mammalian sperm was launched and

Received: July 8, 2016

Accepted: April 6, 2017

*Corresponding author: giovanoneumann@hotmail.com

http://dx.doi.org/10.1590/S1806-92902017000700002

How to cite: Neumann, G.; Bernardes Júnior, J. J.; Sanches, P. V.; Piana, P. A. and Bombardelli, R. A. 2017. Contribution of the CASA system, based on open source software, to the assessment of sperm characteristics: informetric and usage-based approaches. Revista Brasileira de Zootecnia 46(7):560-568.

Copyright (C) 2017 Sociedade Brasileira de Zootecnia. This is an Open Access article distributed under the terms of the Creative Commons Attribution License (http://creativecommons.org/licenses/by/4.0/), which permits unrestricted use, distribution, and reproduction in any medium, provided the original work is properly cited. then evolved into a fully automated system (Amann and Waberski, 2014). Further improvements and bug fixes allowed for other type of cell movements to be evaluated. A pioneering study on fish published in 1985, using concepts of the CASA system, evaluated the relationship between flagellar beating and water temperature in Oncorhynchus mykiss (Cosson et al., 1985). Since then, studies on the movement characteristics and quality of fish sperm have been assessed using a number of sperm trackers of varying degrees of sophistication, each one with its advantages and disadvantages (Kime et al., 2001).

Despite the great potential of CASA systems, their implementation costs were always considerable. Therefore, many researchers have still relied on more subjective methods of motility assessment (Rurangwa et al., 2004; Fauvel et al., 2010; Kalbassi et al., 2013). The subjective methods of motility analysis are practical and simple; however, their accuracy depends on the experience of the evaluator and is more prone to human error (Kime et al., 2001). Moreover, they do not allow for the evaluation of spermatozoa speed and behavior.

This drawback inspired Wilson-Leedy and Ingermann to develop an open source CASA plug-in for ImageJ, using 
JAVA language. The article entitled "Development of a novel CASA system based on open source software for characterization of zebrafish sperm motility parameters" was published in 2007 in the journal Theriogenology and introduced the CASA plug-in to the scientific community.

The CASA plug-in can simultaneously track more than 300 sperm and analyze eight parameters of movement in addition to the number of sperm tracked. Furthermore, given the versatility of open source software, the researcher can employ modifications to fit a particular need for the analysis of sperm or cells of other taxa.

Considering the potential of this tool and easier access to technology, its usage by researchers is expected to gain more momentum over time. Therefore, in the current study, we evaluated the contribution and impact of the open source CASA system on sperm studies using informetric (Bar-Ilan, 2008) and usage-based approaches. Specific analytical procedures performed on fish sperm, described in the searched studies, were assessed to quantify the most frequently used CASA parameters and understand its interpretations and correlations.

\section{Material and Methods}

A literature search of research publications citing the article "Development of a novel CASA system based on open source software for characterization of zebrafish sperm motility parameters" was performed via the ISI Web of Knowledge (Thomson Reuters, Web of Science) platform, from the publication year (2007) until 2014. A search on Google Scholar was also performed to search for books, doctoral dissertations, master's theses, and references not indexed on Web of Science.

All data resulting from the searches were organized by publication type and target organism or purpose (technical contribution or review article) to provide a general framework of the contribution of open source CASA to the studies. Regression analysis was performed to evaluate temporal variation in the number of citations (Zar, 2010). The citation impact of the reference study, considering only the peer-reviewed articles, was also measured by the h-index (Hirsch, 2005).

Articles accessing fish sperm quality using the open source CASA system were filtered and thoroughly examined to characterize the usage of the tool. Overall characteristics such as target species, journal chosen for publication, and country of origin of the study were quantified.

A conceptual map describing the methods of knowledge sharing was constructed, taking into account authorship (lead author and co-authors) and the country of origin of the institution with which the authors were affiliated.

Considering some recommendations for specific methodological procedures using CASA (Kime et al., 2001; Wilson-Leedy and Ingermann, 2007), the varying approaches of the articles were characterized by solutions for preventing sperm from sticking to the slide, the acquisition rate of the videos, and the time of analysis within motility time interval. We also checked if the initial species-specific values (a requirement for the analysis) of the plug-in were described.

The number of parameters describing sperm movements (software outputs) used in the aforementioned articles were counted and the frequencies of all parameters were subjected to a cluster analysis using Euclidean distance as a dissimilarity measure and group-average as a linkage method (Hair et al., 2009).

\section{Results}

The article "Development of a novel CASA system based on open source software for characterization of zebrafish sperm motility parameters" by Wilson-Leedy and Ingermann (2007) was cited 125 times between 2007 and 2014 in four publication types: 97 articles (77.60\%), 13 doctoral dissertations $(10.40 \%)$, nine master's theses (7.20\%), and six books (4.80\%) (Figure 1).

Among the articles quoting the work by Wilson-Leedy and Ingermann (2007), there was a significant increase in citations between the years 2010 and 2014; in general, there was an increase of approximately three citations per

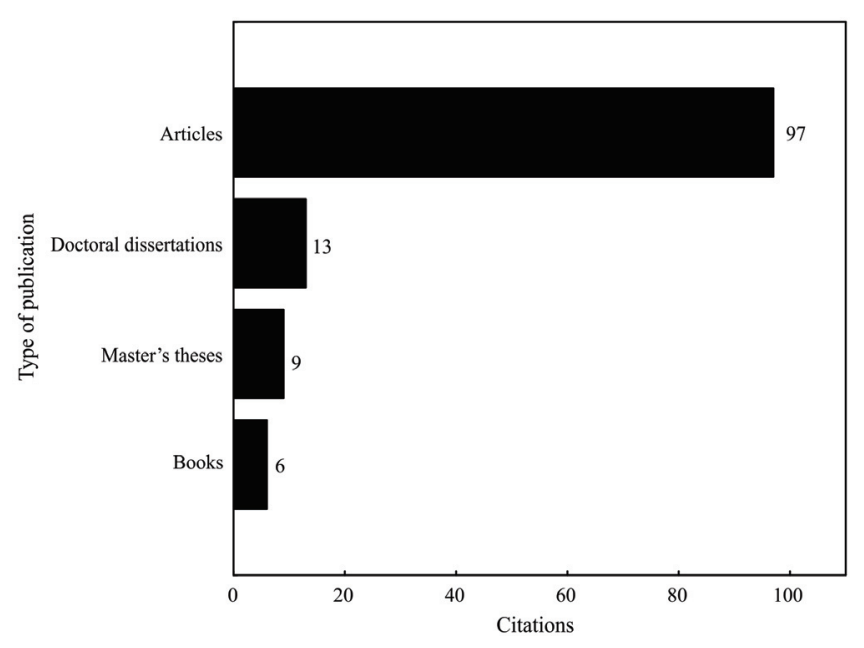

Figure 1 - Incidences of scientific research citing Wilson-Leedy and Ingermann (2007) by publication type. 
year (citations $=-6139.05+3.06$ Year; $\left.\mathrm{R}^{2}=0.90 ; \mathrm{P}<0.01\right)$ (Figure 2). The citation count from the other types of publications was almost constant and stayed below five citations per year. No linear relationship was observed over time $(\mathrm{P}>0.05)$. The calculated h-index was 17 , signifying that there were 17 articles and each one was cited at least 17 times.

Fish were the main group of organisms studied, followed by mammals, marine invertebrates, and birds (Figure 3). Review articles totaled eight and discussions of specific procedures regarding open source or copyrighted CASA systems accounted for two articles. An additional four works citing Wilson-Leedy and Ingermann (2007) pertained to other organisms such as seaweed, plagued protozoa, and amphibians.

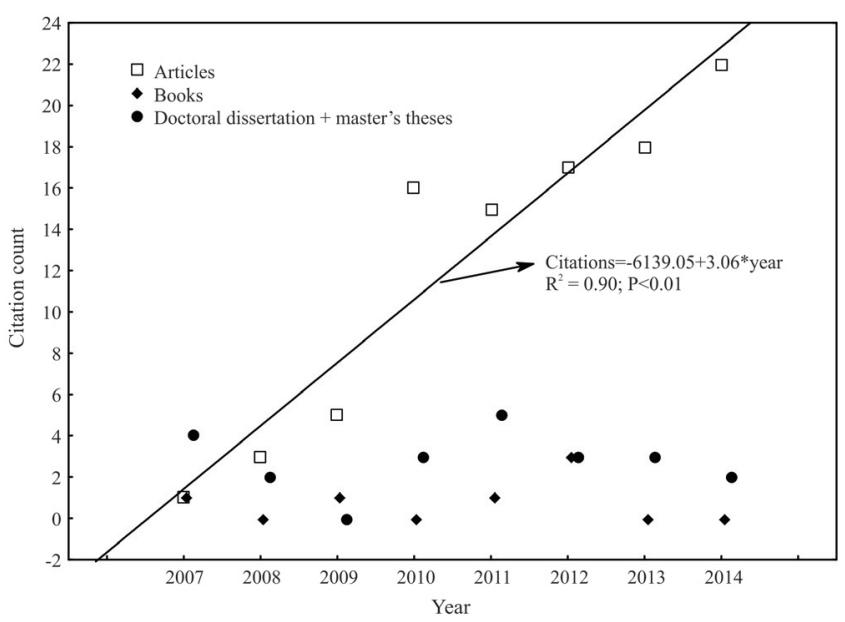

Figure 2 - Annual citations of Wilson-Leedy and Ingermann (2007).

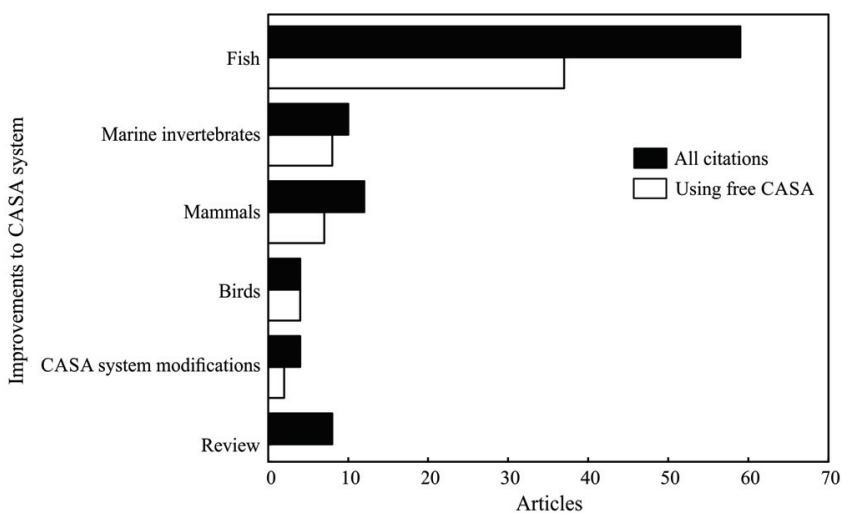

CASA - computer-assisted sperm analysis.

Figure 3 - Number of scientific publications citing Wilson-Leedy and Ingermann (2007) by study objective.
Fifty-five articles that cited Wilson-Leedy and Ingermann (2007) used the CASA plug-in. In those studies, fish sperm movements were evaluated by 34 studies, followed by studies involving marine invertebrates (8), mammalians (7), and birds (4). Two articles proposed technical improvements to the plug-in and other two used the CASA system to assess cellular movements of protozoa and microalgae.

Fish sperm movements of 23 species were examined among the 34 articles that used the CASA plug-in (Table 1). Marine and freshwater species of fish from tropical, subtropical, and temperate climates were studied. Two studies evaluated both fresh and cryopreserved milt and in the remaining 32 articles, only fresh milt was evaluated.

Journal choice was well-diversified. The studies evaluated were published in 21 journals, the three most frequent being from the Journal of Applied Ichthyology, Theriogenology, and Aquaculture Research (Figure 4).

Regarding the country of origin, most of the studies were conducted in the Americas (67.6\%), mainly in the United States (Figure 5). Brazil ranks second with onethird the number of articles that were published in the USA. There were three publications in South Africa, followed by Canada and the Czech Republic with two articles each. The remaining seven countries contributed one article each.

Knowledge about the open source CASA were disseminated in four ways (Figure 6): developers of the open source CASA system initiated partnerships with other institutions, sharing knowledge directly; authors who worked directly with Dr. Jonas Wilson-Leedy or Dr. Rolf Ingermann established new partnerships with other institutions (knowledge multipliers); adoption of the open source CASA system technology occurred via independent initiatives based on the guidelines contained

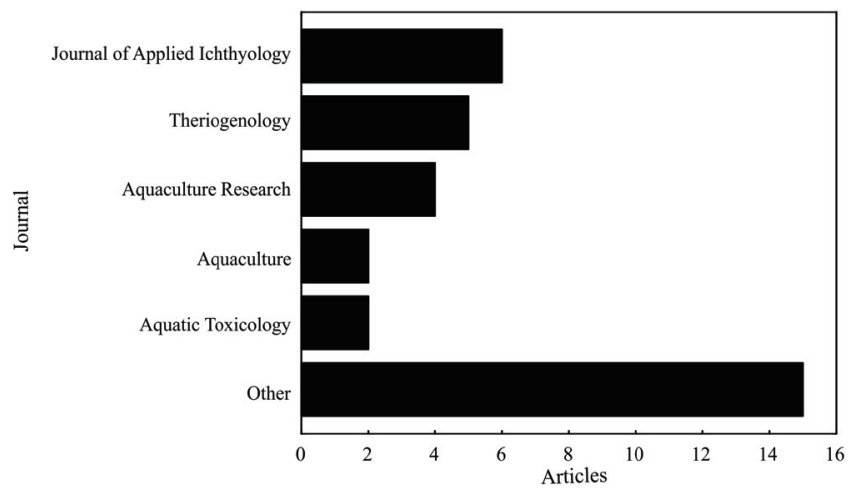

CASA - computer-assisted sperm analysis.

Figure 4 - Frequency of published studies using the open source CASA plug-in developed by Wilson-Leedy and Ingermann (2007), organized by journal. 
in the reference article and the software documentation; expansion of cooperation network from the research group, which adopted the technology via their own initiative (knowledge multipliers).

In addition, there were instances of the direct sharing of knowledge from Wilson-Leedy and Ingermann to researchers in France and the Czech Republic. It seemed that, in succession, French researchers spread their experience to partners in Italy and Greece. The results indicate that independent initiatives have taken place in the use of CASA in free software in other states of the USA

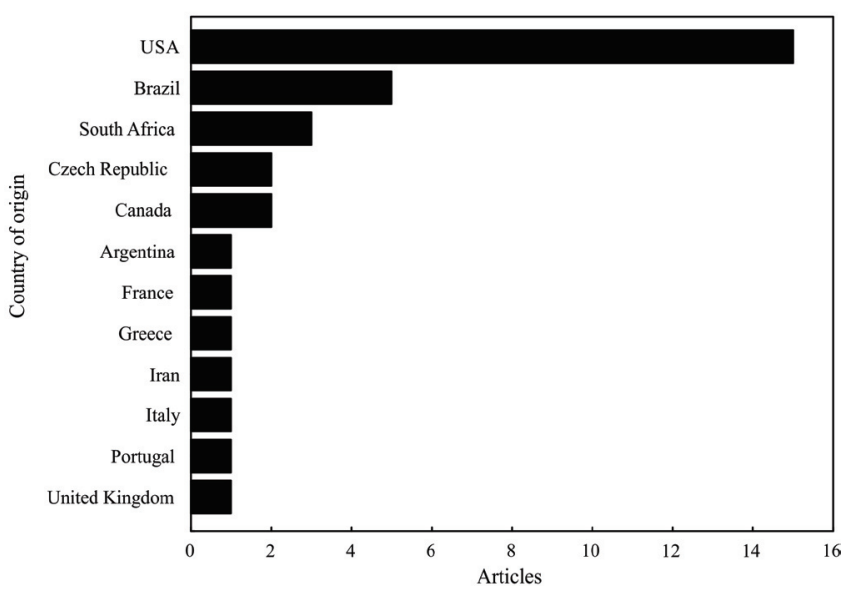

CASA - computer-assisted sperm analysis.

Figure 5 - Country of origin of studies that used the CASA plug-in to evaluate fish sperm.
(Figure 6), Canada, Brazil, United Kingdom, Portugal, South Africa, and Iran, from which they arose through the interpretation and use of the information provided in the article by Wilson-Leedy and Ingermann (2007). A Brazilian research group also expanded the cooperation network to Argentina (Figure 6).

Solutions containing bovine serum albumin (BSA), polyvinyl alcohol, pluronic surfactant, or gelatin were used to reduce the sticking of sperm to slides as described by 15

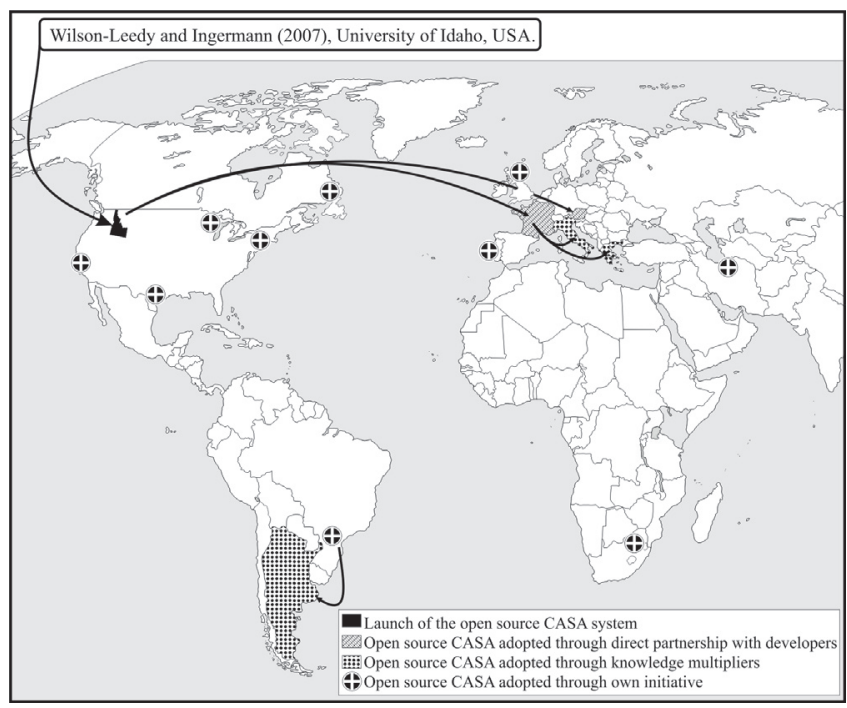

CASA - computer-assisted sperm analysis.

Figure 6 - Conceptual map of knowledge transfer of the open source CASA system.

Table 1 - Fish species studied using CASA plug-in for ImageJ software

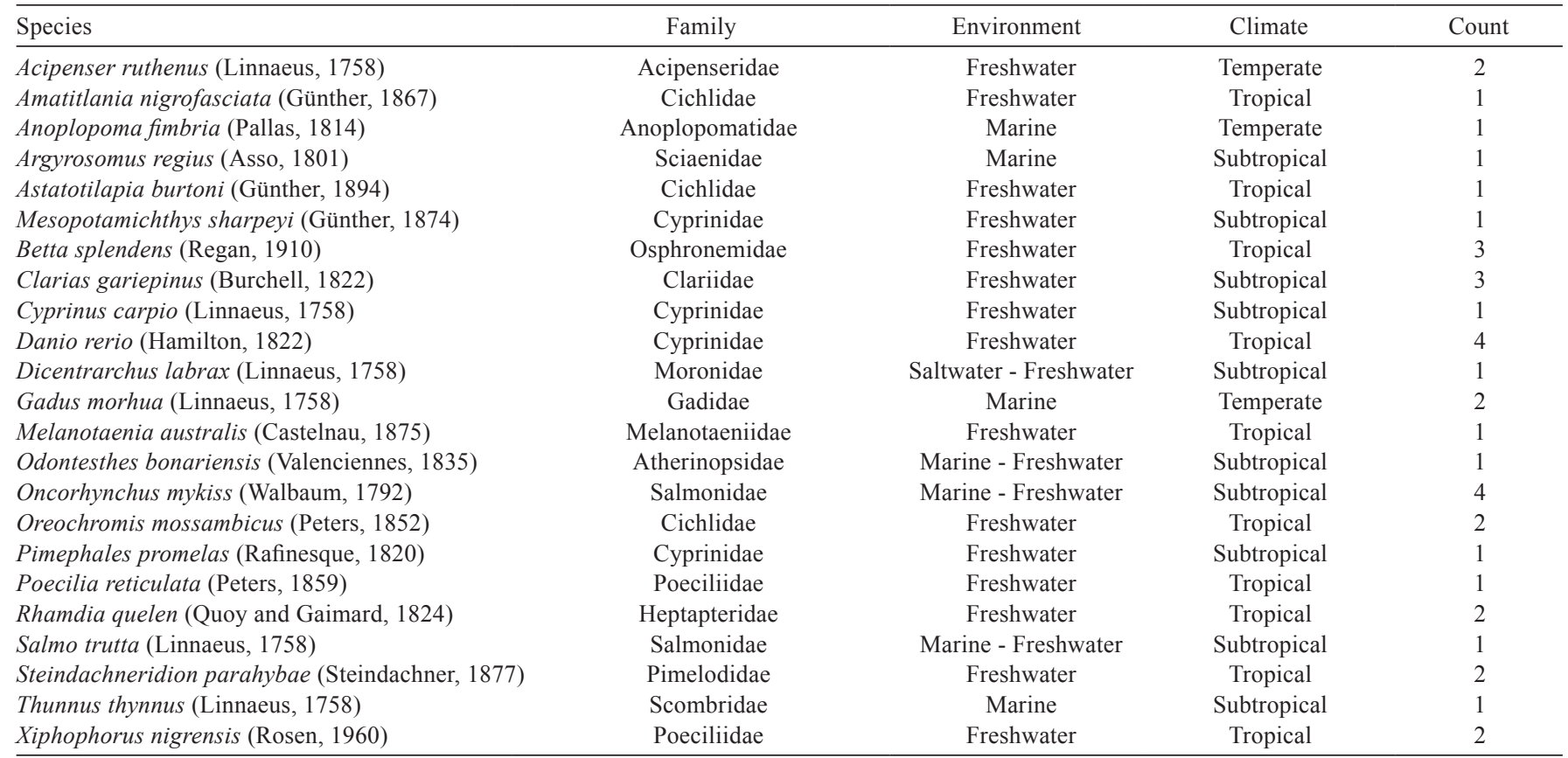

CASA - computer-assisted sperm analysis. 
articles. Some studies did not use or cited (19) this in the methodology.

Depending on the purpose of the study, analyses of sperm movements were performed either at one time (10 articles) or at 1-10-s intervals after activation (20 articles). Only three articles did not specify the time point. The postactivation time chosen was well diversified, ranging from $5 \mathrm{~s}$ to $7 \mathrm{~min}$.

The acquisition rate of videos varied from 16 to $200 \mathrm{fps}$ among the articles, of which $15(44 \%)$ of the studies captured videos at 97-100 fps (Figure 7). Remarkably, seven $(20.6 \%)$ articles did not show or cite (NS) the acquisition rate of the videos. The number of videos recorded per milt sample was showed in 12 articles, ranging from two to five, with three videos being the most frequent number of videos recorded (10 articles).

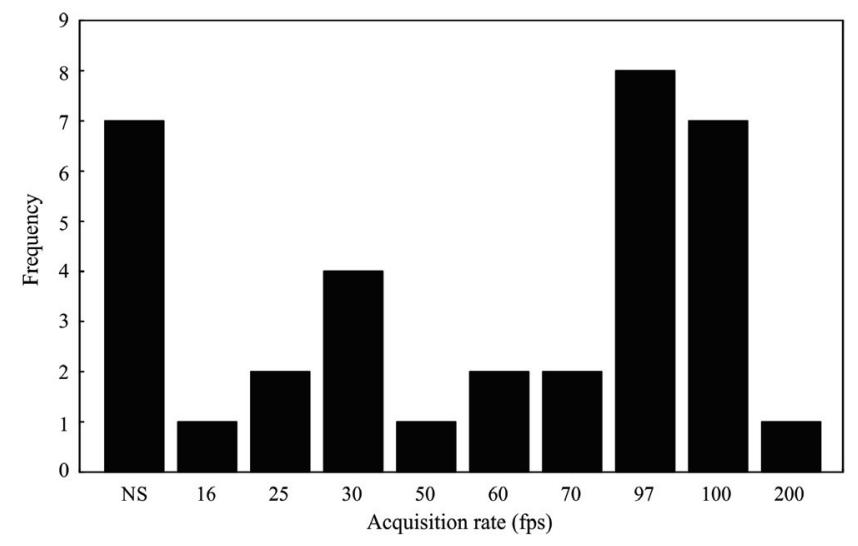

NS - not shown or cited; CASA - computer-assisted sperm analysis.

Figure 7 - Frequency of the acquisition rate of videos of sperm movement in studies that used the CASA plug-in.

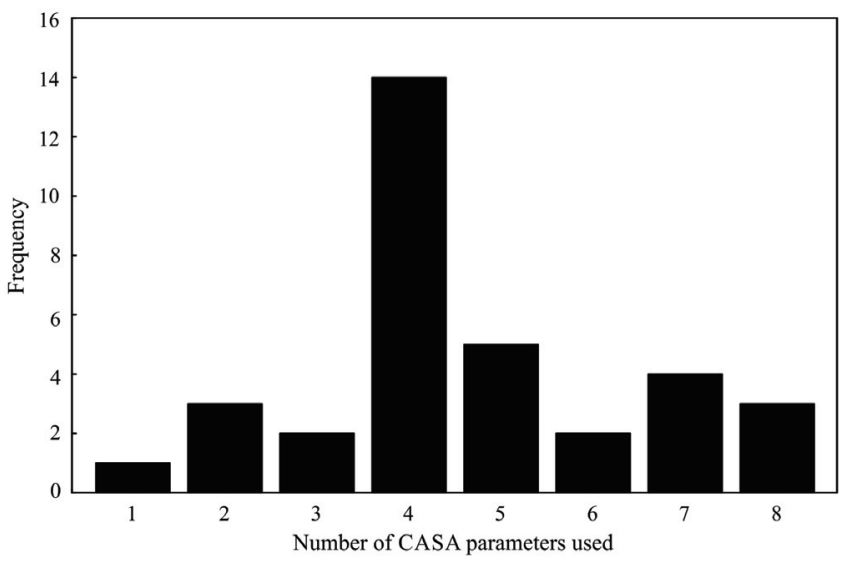

CASA - computer-assisted sperm analysis.

Figure 8 - Number of CASA parameters used in articles studying fish sperm using the open source CASA system.
Regarding the plug-in requirements, less than half of the articles (15) presented or cited the input values of the CASA plug-in. Furthermore, different numbers of output parameters measured by CASA were used among the 34 articles, with the most frequent number of parameters being four (Figure 8). The dendrogram resulted in two homogeneous clusters, separating at a Euclidean distance of 16 (Figure 9). The first cluster represents the output parameters most used by researchers: motility, curvilinear velocity (VCL), average path velocity (VAP), and straightline velocity (VSL). The second cluster joined the output parameters frequently chosen in studies with more than four parameters: linearity, wobble, progression, number of sperm tracked, and beat/cross frequency.

\section{Discussion}

Our best attempt to group the articles via central topics, without underestimating specific goals, provided a clear framework of the software usage. Undoubtedly, the CASA system based on open source software, that arose as a low-cost alternative to more costly analysis programs is simple and highly adaptive for the evaluation of sperm movements.

Over the course of the eight years since the plugin was released by Wilson-Leedy and Ingermann, a cooperative network has been established among groups of researchers in different countries. Nonetheless, it seems that the majority of researchers started using the plug-in by their own initiative. The repercussion was quick, crossing intercontinental barriers as evidenced by the number of countries involved (12). Dozens of studies using the tool

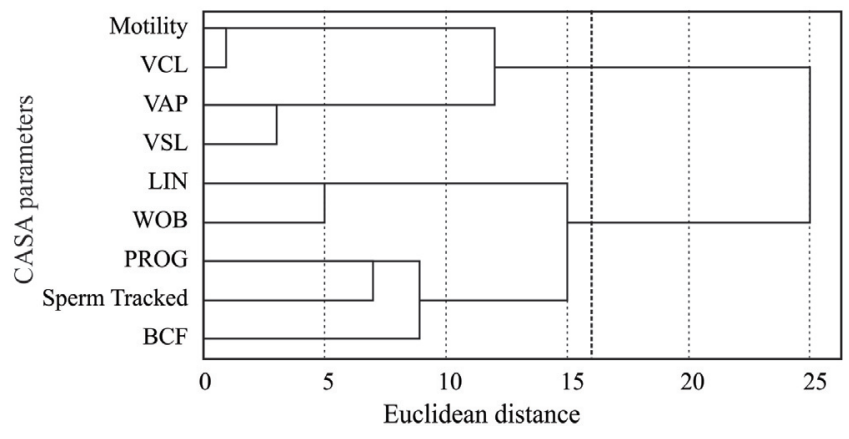

CASA - computer-assisted sperm analysis; VCL - curvilinear velocity; VAP average path velocity; VSL - straight-line velocity; LIN - linearity; WOB - wobble; PROG - progression; SpermTracked - number of sperm tracked; BCF - beat/cross frequency.

Figure 9 - Dendrogram for hierarchical clustering of CASA parameters using Euclidean distance and the groupaverage linkage method. 
were published in several journals and, as expected, the number of citations of the reference article has increased gradually until the present.

Moving away from subjective and semi-quantitative methods of sperm motility assessment towards more objective methods is a natural trend, owing to advances in technology and the cost reduction of objective methods such as CASA, which provide precise and accurate information on different characteristics of sperm motion (Kime et al., 2001). Besides the aforementioned advantages to using CASA, a reduction in the time spent observing sperm and decreases in intra-observer variability are additional advantages (Liu et al., 2007). Therefore, the observed increase in the use of this tool could be due, in part, to these factors.

Computer-assisted sperm analysis supports numerous options for default values, making it possible to apply the analysis to virtually all fish species as well as to other taxa, as observed in mammals (Lemaitre et al., 2012; El-Sherry et al., 2014; Fisher et al., 2014; Jaiswal et al., 2014; Simpson et al., 2014), birds (Helfenstein et al., 2010a, 2010b; Losdat et al., 2011; Simpson et al., 2014), and marine invertebrates (Fitzpatrick et al., 2010; Liu et al., 2011b; Sasson et al., 2012; Suquet et al., 2012; Simpson et al., 2014). As a result, fish sperm from 23 species from diverse environments has been studied to date. Moreover, since displacement is calculated based on the centroid of the particle (spermatozoa head), movements of other kind of cells such as protozoa (Zukas et al., 2012) and microalgae (Liu et al., 2011a) were also assessed using this versatile tool.

The role of some species-specific input values in the plug-in interface serves to accurately detect non-motile sperm. Although the majority of the studies used CASA as a tool, less than a half presented those values in the methodology. The input values should be considered important information in published works as they incorporate the criteria of inclusion or exclusion of sperm from analyzed videos, thereby significantly altering CASA results (Wilson-Leedy and Ingermann, 2007). Furthermore, those values could be used as reference for other research groups working with the same species.

Regarding specific recommendations on analytical procedures, Wilson-Leedy and Ingermann (2007) found a linear relationship between the acquisition rate (30 to $300 \mathrm{fps}$ ) and measured VCL and linearity. They (Wilson-Leedy and Ingermann, 2007) argued that the minimum frame rate with optimal descriptive capability could be identified as the rate beyond which increases in frame rate result in nominal increases in VCL. Based on those findings, the authors recommended an acquisition rate of at least $97 \mathrm{fps}$. Drawing attention to acquisition rates used in the articles cited in this study, in approximately $56 \%$ (19) of the articles, videos were recorded at rates lower than $97 \mathrm{fps}$ or the rate was not cited in methodology. Variations in acquisition rates alone make it impracticable to compare between studies given that that the VCL may be underestimated. The most likely explanation for those variations would be limited access to equipment with the recommended specifications. Cases in which low speed recording is used (e.g., 25 fps), VCL and VAP would be quite similar, and thus VAP would be a more stable measure of velocity (Wilson-Leedy and Ingermann, 2007).

Fish sperm generally has a short period of motility of no longer than a few minutes, with the exception of the sperm from some species of sturgeon, which retain their motility for several hours after activation (Cabrita et al., 2008). Since the velocity decreases quickly after motility initiation, the recordings should be started as soon as possible after mixing with the activation solution. This is especially important in species such as salmonids, in which sperm only remain motile for 20-30 s (Kime et al., 2001). Considering the different approaches of the studies, it seems that specific times or intervals were chosen according to the particular characteristics of each type of sperm, the main objective of the study, or difficulties experienced during milt manipulation. Therefore, of the articles that used the CASA plug-in, the analyses were performed at a single time (Fauvel et al., 2012), at regular intervals for whole duration of motility (Ingermann et al., 2011; Mylonas et al., 2013), or at regular intervals during part of the motility period (Sanches et al., 2010; Boryshpolets et al., 2013; Kalbassi et al., 2013).

Spermatozoa sticking to glass slides or to the counting chamber is another concern in CASA procedures, since a reduction in the percentage of motility spermatozoa can result in an underestimation of the velocity calculation (Billard et al., 1995; Abascal et al., 2007). For this reason, it is recommended to use anti-stick solutions such as BSA or polyvinyl alcohol in the activation media or to coat the slides to prevent sticking (Kime et al., 2001). In contrast, sticking has not been observed in some species of the order Characiformes (Orfão et al., 2011; Nascimento et al., 2012) and thus, in such cases, the use of BSA or other compounds is unnecessary. Whereas approximately half of the articles did not use or did not cite the use of non-stick solutions, it is likely that for other species, sticking is not an issue. Moreover, many scientific journals have space constraints and, thus, the content of the methodology has to be very concise, potentially resulting in the omission of such information. 
A common trend of most of the articles was that sperm was assessed primarily through percent motility and sperm velocities. Due to the high correlation observed between VAP, VCL, and VSL, some studies reported only VCL (Clotfelter and Gendelman, 2014; Purchase and Moreau, 2012; Sullivan et al., 2014), whilst others grouped the parameters by a principal component analysis to express sperm velocity (Simpson et al., 2014; Tessaro et al., 2012).

Swimming patterns described by linearity, wobble, progression, and beat/cross frequency were less exploited. A thorough analysis of the objectives of the studies suggests difficulties, although subtle, in the interpretation of some parameters. Computer-assisted sperm analysis produces a great deal of data, which is often difficult to correlate to specific sperm function (Bobe and Labbé, 2010; Amann and Waberski, 2014). Furthermore, due to the lack of reference values or explanations of the practical reasoning, some parameters seem less valued. Wobble can be useful in understanding the efficiency of the average forward movement and the progression divided by VAP yields a description of the efficiency in terms of the portion of generalized motion that results in movement away from the origin (Ingermann et al., 2011). Beat/cross frequency was the least used variable and was probably avoided due to the recommendation from Wilson-Leedy and Ingermann (2007). This variable calculates the frequency with which the sperm heads cross the average path; thus, for species with paths that are highly circular in nature, very few crosses are counted, resulting in erroneous calculations.

Several articles evaluated both CASA parameters and the final product of reproduction such as fertilization or hatching rates (Kanuga et al., 2011; Stevenson et al., 2011; Fauvel et al., 2012; Kalbassi et al., 2013; Beirão et al., 2014; Immerman and Goetz, 2014; Sanches et al., 2014; Chalde et al., 2016); however, only one study attempted blending this information (Smith, 2012). Smith (2012) evaluated the relationships between sperm viability, velocity, and storage on siring success in Xiphophorus nigrensis. The study found that velocity (VAP) alone failed to predict siring success and demonstrated that the effect of velocity on paternity depended on storage duration, in which males with faster sperm sired fewer offspring when sperm were stored prior to fertilization. In contrast, using an adequate sperm:egg ratio, Rurangwa et al. (2001) showed a positive correlation between sperm velocity (VCL or VSL) and fertilization or hatching rate. Given these results, CASA might possibly predict the best fertilization rate when comparing the quality of different milt samples (Kime et al., 2001). At any given time, the effect of all measures of sperm quality generated by CASA regarding the success of egg fertilization should be validated (Rurangwa et al., 2004; Amann and Waberski, 2014).

Given the increase in fish aquaculture production on a global scale, whose contribution increased from $1 \%$ in 1970 to $48.9 \%$ in 2013 (FAO, 2014), the number of research aimed at reproductive management using CASA is expected to increase in next years. The production of high quality gametes will be essential to the fish production chain and the use of objective methods of sperm assessments, such as CASA, will become more widely used, not only in research, but in farming practices as well.

\section{Conclusions}

Despite being an important tool for quantitative analyses, the potential of the computer-assisted sperm analysis plug-in has not been completely explored. It is our assessment that some results produced by the computerassisted sperm analysis are poorly understood or even misunderstood. In addition, inconsistent results can be produced if the recommended calibration procedures are not followed.

Finally, from the point of view of the total number of publications in the field of sperm analysis in general, the contribution of the open source computer-assisted sperm analysis system seems to be underused, since it is mainly applied in fish evaluations. However, since the technology has already been established in many research groups, the number of publications is expected to continue to grow for years to come.

\section{Acknowledgments}

We thank CAPES (Coordenação de Aperfeiçoamento de Pessoal de Nível Superior) for the scholarship granted to the first and second authors of this paper and ENGIE Tractebel Energia S.A. that, through the Research and Development Program (P\&D) of the National Electric Energy Agency (ANEEL), project under protocol PD0403-0026/2011, helped us.

\section{References}

Abascal, F. J.; Cosson, J. and Fauvel, C. 2007. Characterization of sperm motility in sea bass: the effect of heavy metals and physicochemical variables on sperm motility. Journal of Fish Biology 70:509-522.

Amann, R. P. and Katz, D. F. 2004. Andrology Lab Corner: Reflections on CASA after 25 years. Journal of Andrology 25:317-325. 
Amann, R. P. and Waberski, D. 2014. Computer-assisted sperm analysis (CASA): Capabilities and potential developments. Theriogenology 81:5-17.

Bar-Ilan, J. 2008. Informetrics at the beginning of the 21 st century - A review. Journal of Informetrics 2:1-52.

Beirão, J.; Purchase, C. F.; Wringe, B. F. and Fleming, I. A. 2014. Sperm plasticity to seawater temperatures in Atlantic cod Gadus morhua is affected more by population origin than individual environmental exposure. Marine Ecology Progress Series 495:263-274.

Billard, R.; Cosson, J.; Perchec, G. and Linhart, O. 1995. Biology of sperm and artificial reproduction in carp. Aquaculture 129:95-112.

Bobe, J. and Labbé, C. 2010. Egg and sperm quality in fish. General and Comparative Endocrinology 165:535-548.

Boryshpolets, S.; Cosson, J.; Bondarenko, V.; Gillies, E.; Rodina, M.; Dzyuba, B. and Linhart, O. 2013. Different swimming behaviors of sterlet (Acipenser ruthenus) spermatozoa close to solid and free surfaces. Theriogenology 79:81-86.

Cabrita, E.; Robles, V. and Herráez, P. 2008. Sperm quality assessment. p.93-147. In: Methods in reproductive aquaculture: marine and freshwater species. Cabrita, E.; Robles, V. and Herráez, P., eds. E-Publishing Inc, Florida.

Chalde T.; Gárriz, Á.; Sanches, E. A. and Miranda, L. A. 2016. Influence of pejerrey Odontesthes bonariensis (Valenciennes, 1835) broodstock age on gamete quality, reproductive performance and plasma sex steroid levels during the spawning season. Aquaculture Research 47:969-982.

Clotfelter, E. D. and Gendelman, H. K. 2014. Exposure to environmentally relevant concentrations of genistein during activation does not affect sperm motility in the fighting fish Betta splendens. BioMed Research International 2014:1-5.

Cosson, M-P.; Billard, R.; Gatti, J. L. and Christen, R. 1985. Rapid and quantitative assessment of trout spermatozoa motility using stroboscopy. Aquaculture 46:71-75.

El-Sherry, T. M.; Elsayed, M.; Abdelhafez, H. K. and Abdelgawad, M. 2014. Characterization of rheotaxis of bull sperm using microfluidics. Integrative Biology 6:1111-1121.

FAO - Food and Agriculture Organization of the United Nations. 2014. The state of world fisheries and aquaculture 2014: Opportunities and challenges. Food and Agriculture Organization of the United Nations, Rome.

Fauvel, C.; Boryshpolets, S.; Cosson, J.; Leedy, J. G. W.; Labbe, C.; Haffray, P. and Suquet, M. 2012. Improvement of chilled seabass sperm conservation using a cell culture medium. Journal of Applied Ichthyology 28:961-966.

Fauvel, C.; Suquet, M. and Cosson, J. 2010. Evaluation of fish sperm quality. Journal of Applied Ichthyology 26:636-643.

Fisher, H. S.; Giomi, L.; Hoekstra, H. E. and Mahadevan, L. 2014. The dynamics of sperm cooperation in a competitive environment. Proceedings of the Royal Society of London B 281:1-21.

Fitzpatrick, J. L.; Garcia-Gonzalez, F. and Evans, J. P. 2010. Linking sperm length and velocity: the importance of intramale variation. Biology Letters 6:797-799.

Hair, J. F.; Black, W. C.; Babin, B. J.; Anderson, R. E. and Tatham, R. L. 2009. Análise multivariada de dados. 6.ed. Bookman, Porto Alegre.

Helfenstein, F.; Losdat, S.; Møller, A. P.; Blount, J. D. and Richner, H. 2010a. Sperm of colourful males are better protected against oxidative stress. Ecology Letters 13:213-222.

Helfenstein, F.; Podevin, M. and Richner, H. 2010b. Sperm morphology, swimming velocity, and longevity in the house sparrow Passer domesticus. Behavioral Ecology and Sociobiology 64:557-565.
Hirsch, J. E. 2005. An index to quantify an individual's scientific research output. Proceedings of the National Academy of Sciences of the USA 102:16569-16572.

Immerman, D. A. and Goetz, F. W. 2014. The activation and cryopreservation of sablefish (Anoplopoma fimbria) sperm. Aquaculture 430:211-217.

Ingermann, R. L.; Schultz, C. L. F.; Kanuga, M. K. and Wilson-Leedy, J. G. 2011. Metabolism of motile zebrafish sperm. Comparative Biochemistry and Physiology - Part A 158:461-467.

Jaiswal, M. K.; Katara, G. K.; Mallers, T.; Chaouat, G.; GilmanSachs, A. and Beaman, K. D. 2014. Vacuolar-ATPase isoform a2 regulates macrophages and cytokine profile necessary for normal spermatogenesis in testis. Journal of Leukocyte Biology 96:337-347.

Kalbassi, M. R.; Lorestani, R. and Maramazi, J. G. 2013. Analysis of saline activator solution effects on sperm quality indices of Barbus sharpeyi by Image J software. Iranian Journal of Fisheries Sciences 12:357-377.

Kanuga, M. K.; Benner, M. J.; Doble, J. A.; Wilson-Leedy, J. G.; Robison, B. D. and Ingermann, R. L. 2011. Effect of Aging on Male Reproduction in Zebrafish (Danio rerio). Journal of Experimental Zoology Part A 315A:156-161.

Kime, D. E.; Van Look, K. J. W.; McAllister, B. G.; Huyskens, G.; Rurangwa, E. and Ollevier, F. 2001. Computer-assisted sperm analysis (CASA) as a tool for monitoring sperm quality in fish. Comparative Biochemistry and Physiology Part C 130:425-433.

Lemaitre, J. F.; Ramm, S. A. and Hurst, J. L. 2012. Stockley P. Sperm competition roles and ejaculate investment in a promiscuous mammal. Journal of Evolutionary Biology 25:1216-1225.

Liu, G. X.; Chai, X. L.; Shao, Y. Q.; Hu, L. H.; Xie, Q. L. and Wu, H. X. 2011a. Toxicity of copper, lead, and cadmium on the motility of two marine microalgae Isochrysis galbana and Tetraselmis chui. Journal of Environmental Sciences (China) 23:330-335.

Liu, G. X.; Innes, D. and Thompson, R. J. 2011b. Quantitative analysis of sperm plane circular movement in the blue mussels Mytilus edulis, M. trossulus and their hybrids. Journal of Experimental Zoology Part A 315A:280-290.

Liu, Q. H.; Li, J.; Xiao, Z. Z.; Ding, F. H.; Yu, D. D. and Xu, X. Z. 2007. Use of computer-assisted sperm analysis (CASA) to evaluate the quality of cryopreserved sperm in red seabream (Pagrus major). Aquaculture 263:20-25.

Losdat, S.; Richner, H. Blount, J. D. and Helfenstein, F. 2011. Immune activation reduces sperm quality in the Great Tit. Plos One 6:6-10.

Mylonas, C. C.; Mitrizakis, N.; Papadaki, M. and Sigelaki, I. 2013. Reproduction of hatchery-produced meagre Argyrosomus regius in captivity I. Description of the annual reproductive cycle. Aquaculture 414-415:309-317.

Nascimento, A. F.; Gonçalves, A. C. S.; Reis-Neto, R. V.; Leal, M. C. and Viveiros, A. T. M. 2012. Extender composition, osmolality, cryoprotectant and equilibration time effects on fresh sperm motility of two Characiformes fish: piracanjuba (Brycon orbignyanus) and streaked prochilod (Prochilodus lineatus). Animal Reproduction 9:103-110

Orfão, L. H.; Nascimento, A. F.; Corrêa, F. M.; Cosson, J. and Viveiros, A. T. M. 2011. Extender composition, osmolality and cryoprotectant effects on the motility of sperm in the Brazilian endangered species Brycon opalinus (Characiformes). Aquaculture 311:241-247.

Purchase, C. F. and Moreau, D. T. R. 2012. Stressful environments induce novel phenotypic variation: hierarchical reaction norms for sperm performance of a pervasive invader. Ecology Evolution 2:2567-2576.

Rurangwa, E.; Kime, D. E.; Ollevier, F. and Nash, J. P. 2004. The measurement of sperm motility and factors affecting sperm quality in cultured fish. Aquaculture 234:1-28. 
Rurangwa, E.; Volckaert, F. A. M.; Huyskens, G.; Kime, D. E. and Ollevier, F. 2001. Quality control of refrigerated and cryopreserved semen using computer-assisted sperm analysis (CASA), viability staining and standardised fertilisation in African Catfish. Theriogenology 55:751-769.

Sanches, E. A.; Bombardelli, R. A.; Marcos, R. M.; Neumann, G.; Toledo, C. P. R. and Romagosa, E. 2010. Sperm motility of Rhamdia quelen studied using computer-assisted analysis by open-source software. Aquaculture Research 42:153-156.

Sanches, E. A.; Okawara, R.Y.; Caneppele, D.; Neumann, G.; Bombardelli, R. A. and Romagosa, E. 2014. Storage of Steindachneridion parahybae oocytes at different temperatures. Animal Reproduction Science 151:262-268.

Sasson, D. A.; Johnson, S. L. and Brockmann, H. J. 2012. The role of age on sperm traits in the American horseshoe crab, Limulus polyphemus. Animal Behaviour 84:975-981.

Simpson, J. L.; Humphries, S.; Evans, J. P.; Simmons, L. W. and Fitzpatrick, J. L. 2014. Relationships between sperm length and speed differ among three internally and three externally fertilizing species. Evolution 68:92-104.

Smith, C. C. 2012. Opposing effects of sperm viability and velocity on the outcome of sperm competition. Behavioral Ecology 23:820-826.
Stevenson, L. M.; Brown, A. C.; Montgomery, T. M. and Clotfelter, E. D. 2011. Reproductive consequences of exposure to waterborne phytoestrogens in male fighting fish Betta splendens. Archives of Environmental Contamination and Toxicology 60:501-510.

Sullivan, M.; Brown, A. C. and Clotfelter, E. D. 2014. Dietary carotenoids do not improve motility or antioxidant capacity in cichlid fish sperm. Fish Physiology and Biochemistry 40:1399-1405.

Suquet, M.; Le-Mercier, A.; Rimond, F.; Mingant, C.; Haffray, P. and Labbe, C. 2012. Setting tools for the early assessment of the quality of thawed Pacific oyster (Crassostrea gigas) D-larvae. Theriogenology 78:462-467.

Tessaro, L.; Toledo, C. P. R.; Neumann, G.; Krause, R. A.; Meurer, F.; Natali, M. R. M. and Bombardelli, R. A. 2012. Growth and reproductive characteristics of Rhamdia quelen males fed on different digestible energy levels in the reproductive phase. Aquaculture 326-329:74-80.

Wilson-Leedy, J. G. and Ingermann, R. L. 2007. Development of a novel CASA system based on open source software for characterization of zebrafish sperm motility parameters. Theriogenology 67:661-672.

Zar, J. H. 2010. Biostatistical analysis. 7th ed. Prentice Hall, New Jersey.

Zukas, R.; Chang, A. J.; Rice, M. and Springer, A. L. 2012. Structural analysis of flagellar axonemes from inner arm dynein knockdown strains of Trypanosoma brucei. Biocell 36:133-141. 